\title{
CORRECTION
}

\section{Correction: Functional magnetic resonance: biomarkers of response in breast cancer}

\author{
Elizabeth AM O'Flynn* and Nandita M deSouza \\ See related review by O'Flynn and deSouza, http://breast-cancer-research.com/content/13/1/204
}

Upon publication of our article [1], we noticed that the wrong image had been uploaded for Figure 6a. The figure as it should appear can be found below.

\section{Competing interests}

The authors declare that they have no competing interests.

Published: 30 June 2011

\section{References}

1. O'Flynn EA, Desouza NM: Functional magnetic resonance: biomarkers of response in breast cancer. Breast Cancer Res 2011, 13:204.

doi:10.1186/bcr2910

Cite this article as: O'Flynn EAM, deSouza NM: Correction: Functional

magnetic resonance: biomarkers of response in breast cancer. Breast Cancer Research 2011, 13:405.
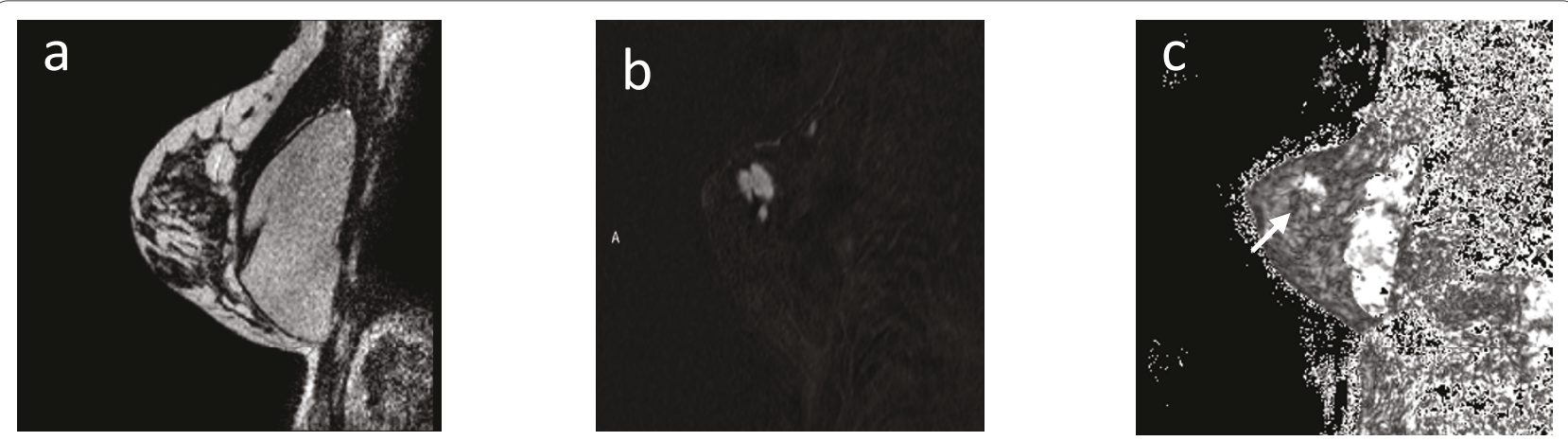

Figure 6. $T_{2}{ }^{*} W$ images of a breast tumour. (a-c) Sagittal T2W (a), dynamic contrast-enhanced (DCE) subtracted image at time point 2.44 minutes (b), and $T_{2}^{*} W$ image (c) in a patient with a palpable breast lump in the upper outer quadrant. The tumour seen in (a) and highlighted in (b) shows heterogeneity of $\mathrm{T}_{2}^{*}$ with faster signal decay in the inferior part of the tumour, indicating a greater deoxyhaemoglobin content here.

*Correspondence: Elizabeth.OFlynn@icr.ac.uk

Clinical Magnetic Resonance Group, Institute of Cancer Research, Royal Marsden

NHS Foundation Trust, Sutton, Surrey, SM2 5PT, United Kingdom 